\title{
Perencanaan Saluran Drainase Perkotaan Wilayah Kecamatan Johan Pahlawan dengan Aplikasi HEC-RAS
}

\author{
Deva Canubry ${ }^{1}$ Azmeri $^{2}$ Nina Shaskia ${ }^{3}$ \\ ${ }^{1}$ Mahasiswa, Jurusan Teknik Sipil, Universitas Syiah Kuala, Banda Aceh 23111, Indonesia \\ ${ }^{2,3}$ Dosen, jurusan Teknik Sipil, Universitas Syiah Kuala, Banda Aceh 23111, Indonesia. \\ Email: canubry.deva@gmail.com
}

\begin{abstract}
Krueng Leuhan River is located between Leuhan Village and Blang Berandang Village. This river serves as the primary drainage channel for the two villages. This channel often overflows when the rainy season comes. Overflow occurs due to sedimentation downstream of the channel. This study aims to analyze the storage capacity of the channel using the HEC-RAS application, as well as to provide suggestions for effective flood management. The channel under review is limited from the tip of Leuhan village to the downstream towards the Krueng Meureubo river. The catchment area (DTA) was taken from the 2 villages studied with a total area of $11.42 \mathrm{~km}^{2}$. The length of the channel under study is $6.5 \mathrm{~km}$, with a river slope of 0.00046. Rain data comes from Cut Nyak Dhien Station for 12 years (2003-2014). The flood discharge was calculated using the Modified Rational Method. Based on the results of this study, the selected mitigation method is structural in the form of river normalization.
\end{abstract}

Keyword: Drainage, river, flood, Leuhan, normalization, HEC-RAS

\begin{abstract}
Abstrak
Sungai Krueng Leuhan terletak di antara Gampong Leuhan dan Gampong Blang Berandang. Sungai ini berfungsi sebagai saluran drainase primer bagi kedua gampong tersebut. Saluran ini kerap meluap ketika musim hujan datang. Luapan terjadi disebabkan adanya sedimentasi di hilir saluran dan elevasi dasar yang sangat beragam disepanjang saluran, sehingga dibutuhkan penelitian tentang kemampuan saluran ketika dialiri debit banjir. Penelitian ini bertujuan untuk menganalisa kapasitas tampungan saluran tersebut menggunakan aplikasi HEC-RAS, serta memberikan saran penanggulan banjir yang efektif. Saluran yang ditinjau dibatasi dari mulai ujung Gampong Leuhan sampai hilir menuju sungai Krueng Meureubo. Luas daerah tangkapan airnya adalah $11,42 \mathrm{~km}^{2}$. Panjang saluran yang ditinjau adalah 6,5 km, dengan kemiringan sungai 0,00046. Data hujan berasal dari Stasiun Cut Nyak Dhien selama 12 tahun (2003-2014). Metode penelitian yang digunakan adalah dengan menghitung debit banjir dengan metode Rasional Modifikasi, kemudian dilanjutkan dengan analisa hidrolika dalam Aplikasi HEC-RAS. Berdasarkan hasil analisa tersebut metode penanggulangan yang dipilih adalah metode struktural berupa normalisasi sungai. Setelah dilakukan normalisasi sungai, tidak lagi terjadi luapan banjir di sepanjang sungai.
\end{abstract}

Kata Kunci: Drainase, sungai, banjir, Leuhan, normalisasi, HEC-RAS

\section{Pendahuluan}

Gampong Leuhan dan gampong Blang Berandang adalah kawasan pemukiman yang sering dilanda banjir. Banjir ini berasal dari luapan sungai Krueng Leuhan yang berada di antara kedua gampong tersebut. Sungai ini berfungsi sebagai saluran drainase primer bagi kedua gampong tersebut. Pola aliran dalam saluran ini sudah sesuai dengan kondisi topografi, akan tetapi terdapat sedimentasi di beberapa titik sepanjang saluran. Sedimentasi ini menyebabkan arus balik sehingga tinggi muka air di sepanjang saluran naik[1]. Oleh karena itu, untuk mengatasi dan mencegah kembali terjadinya banjir di daerah ini dibutuhkan analisa tentang permasalahan apa yang terjadi pada saluran tersebut.
Saluran drainase memiliki fungsi sebagai tempat mengalirnya limpasan air hujan sehingga kapasitasnya harus dijaga tetap mampu menampung seluruh limpasan air hujan dari daerah tangkapan airnya[2].

Penelitian ini bertujuan untuk mengevaluasi kapasitas saluran drainase eksisting, memberikan alternatif terbaik untuk menanggulangi banjir, dan merencanakan dimensi saluran drainase yang aman banjir. Metode yang dilakukan untuk mengevaluasi banjir adalah dengan menghitung debit banjir rencana meggunakan metode Rasional dari curah hujan harian tahunan di daerah tersebut. Kemudian data debit tersebut di-input ke aplikasi HEC-RAS dan disandingkan dengan data sungai eksisting. Metode ini serupa dengan kajian terdahulu yang pernah dilakukan 
pada sungai Bolifar, Provinsi Maluku[3].

Metode-metode yang dapat digunakan sebagai alternatif penanggulangan banjir dapat berupa secara struktural maupun non-struktural. Secara struktural, metode yang lazim digunakan adalah dengan melakukan normalisasi saluran, pembangunan kolam retensi, pembangunan tanggul penahan banjir, pembangunan sudetan, pembuatan floodway, hingga pembangunan bendung. Secara non-struktural dapat dilakukan dengan melakukan penyuluhan kepada masyarakat tentang permasalahan banjir, kemudian mengatur tata guna lahan di daerah tersebut[4]. Metode yang digunakan disesuaikan dengan permasalah yang terjadi pada saluran tersebut. Setelah dilakukan analisa dan dirasa metode-metode pencegahan banjir tersebut tidak mampu mengatasi permasalahan yang terjadi di saluran, maka akan dilakukan perencanaan ulang drainase sesuai debit banjir daerah tersebut.

Batasan penelitian ini hanya pada drainase primer yang melingkup gampong Leuhan dan gampong Blang Berandang, dan hanya meninjau dari segi perencanaan penanggulangan banjir secara struktural berdasarkan analisa hidrologi dan analisa kapasitas tampungan saluran.

\section{Metodologi penelitian}

\subsection{Obyek penelitian}

Perencanaan ini dilakukan di sungai Krueng Leuhan yang terletak di antara gampong Leuhan dan gampong Blang Berandang, Kecamatan Johan Pahlawan, Kabupaten Aceh Barat, Provinsi Aceh. Secara geografis Kecamatan Johan Pahlawan berada pada titik koordinat 04॰ 11' 56" LU dan 96॰ 07' 15" BT. Gampong Leuhan dan gampong Blang Beurandang memiliki luas total 11,42 km²[5].

\subsection{Jenis dan sumber data}

Perencanaan ini hanya menggunakan data sekunder. Data sekunder didapatkan dari penelitian yang telah lebih dahulu dilakukan berupa peta tata guna lahan gampong Leuhan dan gampong Blang Berandang tahun 2018, peta geometri sungai Krueng Leuhan, dan hasil pengukuran penampang melintang sungai per piasnya. Lalu didapatkan pula data curah hujan bentang tahun 2003 hingga 2014 dari stasiun Meteorologi Cut Nyak Dhien.

\subsection{Teknik analisis}

Dasar dari perencanaan ini adalah dengan menggabungkan data hidrologi dan data hidrolika. Data hidrologi akan dihitung secara manual hingga mendapat hasil berupa debit banjir rencana. Data hidrolika akan dianalisa di dalam HEC-RAS hingga didapatkan hasil berupa kapasitas drainase eksisting.

\subsubsection{Analisa hidrologi}

Hidrologi adalah ilmu yang berkaitan dengan air di bumi, baik mengenai terjadinya, peredaran dan penyebarannya, sifat-sifatnya dan hubungan dengan lingkungannya terutama dengan makhluk hidup [6]. Ilmu hidrologi sangat dipengaruhi oleh parameterparameter hidrologi pada suatu daerah seperti intensitas hujan, kondisi klimatologi (angin, suhu udara, kelembapan udara, dan penyinaran matahari), kondisi lahan (DAS) seperti jenis tanah, tata guna lahan, kemiringan lahan, dan sebagainya.

Analisa hidrologi yang dipakai dalam perencanaan ini adalah dengan menggunakan metode Rasional Modifikasi. Metode ini dapat digunakan karena sesuai dengan kondisi data dan kondisi lapangan yang ada. Metode ini digunakan dengan anggapan bahwa DTA memiliki luas $<300 \mathrm{~km}^{2}$ [4]. Parameter-parameter yang dibutuhan untuk perhitungan debit banjir metode ini adalah intensitas hujan, waktu konsentrasi, koefisien limpasan, dan koefisien tampungan. Rumus menghitung debit banjir metode Rasional Modifikasi adalah:

$Q=0,278$ C.Cs.I.A

Dengan:

$\mathrm{C}=$ koefisien limpasan air hujan;

Cs = koefisien tampungan;

I = intensitas curah hujan selama waktu konsentrasi ( $\mathrm{mm} / \mathrm{jam})$;

A = luas daerah pengaliran $\left(\mathrm{km}^{2}\right)$; dan

$\mathrm{Q}=$ debit maksimum $\left(\mathrm{m}^{3} / \mathrm{det}\right)$.

\subsubsection{Analisa Hidrolika}

Dalam perencanaan ini untuk mengevaluasi saluran drainase hanya digunakan analisa aliran permanen. Untuk mempermudah penelitian digunakan aplikasi HEC-RAS. HEC-RAS adalah aplikasi yang dikembangkan oleh Hydrologic Engineering Center US Army. Aplikasi HEC-RAS ini menitik beratkan pada analisa Hidraulika sebuah sungai. Analisis yang dilakukan oleh HEC-RAS adalah analisis aliran permanen dan tidak permanen[5].

Pada aliran permanen HEC-RAS memakai persamaan energi kecuali di tempat-tempat yang kedalaman airnya melewati kedalaman kritis. Di tempat terjadi loncat air, pertemuan alur, dan aliran dangkal melalui jembatan, HEC-RAS menggunakan persamaan (kekekalan) momentum. Di tempat terjenun, aliran melalui peluap, dan aliran melalui bendung, HEC-RAS menggunakan persamaan-persamaan empiris[6]. Rumus persamaan energi yang digunakan adalah[7]:

$Y_{1}+Z_{1}+\frac{V_{1}^{2}}{2 g}=Y_{2}+Z_{2}+\frac{V_{2}^{2}}{2 g}+\sum h_{f}$

Dengan:

$Y_{1}, Y_{2} \quad=$ kedalaman aliran $(\mathrm{m})$;

$Z_{1}, Z_{2} \quad$ = elevasi dasar saluran $(\mathrm{m})$;

$V_{1}, V_{2} \quad=$ kecepatan rata-rata $(\mathrm{m} / \mathrm{s})$

g $\quad=$ percepatan gravitasi $\left(\mathrm{m} / \mathrm{s}^{2}\right) ;$ dan

$\sum h_{f} \quad=$ total kehilangan energi $(\mathrm{m})$.

\subsubsection{Alternatif Penanggulangan Banjir}

Pada dasarnya pengendalian banjir merupakan suatu upaya untuk mengendalikan air sungai agar tidak meluap melebihi batas sungai. Kegiatan ini dapat 
dilakukan dengan berbagai cara, namun harus dipertimbangkan dan dicari sistem yang paling efektif pada lokasi yang diteliti. Menurut teknis penanganan pengendalian banjir dapat dibedakan menjadi dua metode yaitu metode struktural dan metode nonstruktural [8].

Metode struktural adalah metode pengendalian banjir secara teknis. Metode ini akan memberikan efek langsung terhadap daerah yang terdampak banjir[6]. Upaya yang dapat dilakukan dalam metode ini ada dua, yaitu dengan membangun bangunan pengendali banjir seperti bendungan/waduk, retarding basin, dan pembuatan polder. Selain itu upaya yang dapat dilakukan adalah dengan sistem perbaikan dan pengaturan alur sungai, seperti pekerjaan normalisasi alur sungai, tanggul, sudetan, dan floodway.

Upaya non-struktural merupakan upaya penyesuaian dan pengaturan kegiatan manusia supaya harmonis dan serasi dengan lingkungan. Contoh upaya non-struktural adalah pengaturan maupun pengendalian penggunaan lahan atau tata ruang, penegakan peraturan/hukum, pengawasan penyuluhan kepada masyarakat, dan lainlain [9].

Kegiatan utama yang akan diterapkan adalah normalisasi saluran. Dimensi penampang saluran yang baru akan di rencanakan pada ruas-ruas saluran yang mengalami overtopping. Kemudian jika diketahui setelah dilakukan normalisasi masih terdapat luapan di saluran, maka akan direncanakan pembuatan tanggul saluran.

\section{Hasil dan pembahasan}

\subsection{Kondisi eksisting}

Sungai Krueng Leuhan merupakan anak sungai dari sungai Krueng Meureubo. Sungai ini merupakan saluran alami yang dapat difungsikan sebagai drainase primer dari Gampong Leuhan dan Gampong Blang Berandang. Tebing saluran masih berupa tanah yang ditumbuhi tumbuh-tumbuhan merambat, sedangkan dasar sungai adalah tanah. Pada keadaan normal, debit yang mengalir di sepanjang $\mathrm{Kr}$. Leuhan cenderung lambat dengan tinggi muka air yang rendah.

Selain itu di bagian hilir saluran terdapat sedimentasi yang terjadi di muara menuju sungai $\mathrm{Kr}$. Meureubo. Situasi ini mengakibatkan terciptanya arus balik. Akibatnya tercipta genangan air yang cukup tinggi dan berpotensi menggenangi daerah-daerah disekitarnya. Pada saat terjadi debit yang cukup tinggi perisitiwa ini dapat menaikkan tinggi muka air di sepanjang sungai $\mathrm{Kr}$. Leuhan hingga melewati batas tebing saluran.

\subsection{Analisa Debit Banjir Rencana}

Debit banjir rencana yang digunakan pada perencanaan ini dihitung berdasarkan curah hujan yang berasal dari satu stasiun meteorologi dengan rencana periode ulang 10 tahun. Curah hujan rencana dianalisa dengan distribusi yang dipilih yaitu distribusi Log Pearson III[4]. Curah hujan rencana yang didapat adalah $154,791 \mathrm{~mm}$.

Journal of The Civil Engineering Student Vol. 3. No. 3, Desember 2021, Halaman 282-286
Sebelum menghitung debit banjir rencana di suatu kawasan, curah hujan yang sebelumnya sudah didapat harus ditransformasi terlebih dahulu menjadi intensitas hujan. Untuk kasus ini metode Mononobe sudah cukup efektif untuk digunakan. Hasil intensitas hujan yang didapat adalah 32,208 mm/jam.

Selanjutnya, debit banjir rencana dianalisa dengan rumus rasional modifikasi. Debit banjir yang dihasilkan dari perhitungan ini adalah $35,864 \mathrm{~m}^{3} /$ detik.

\subsection{Kapasitas Tampungan}

Panjang saluran ini ditinjau dari ujung Gampong Leuhan adalah $6,5 \mathrm{~km}$ dengan total 66 cross section dari hulu ke hilir. Jarak antar cross section adalah 100 meter. Tanggul saluran ini masih berupa tanah yang ditumbuhi tumbuhan merambat dan dasar saluran berupa tanah berbatu sehingga koefisien manning yang digunakan adalah 0,03. Koefisien kontraksi yang digunakan adalah 0,1 , sedangkan koefisien ekspansi yang digunakan adalah 0,3. Kemiringan saluran dari hulu ke hilir adalah 0,00046 .

Setelah dilakukan simulasi kapasitas tampungan saluran dengan debit banjir periode ulang 10 tahun, terjadi overtopping pada beberapa titik cross section saluran, terutama pada bagian hilir saluran. Gambaran profil penampang memanjang dapat dilihat pada gambar berikut.

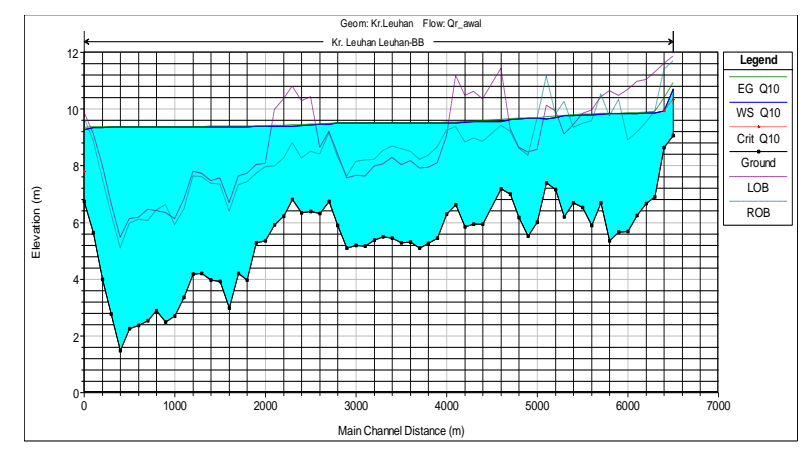

Gambar 1. Profil memanjang sungai Krueng Leuhan kondisi eksisting

Dari gambar tersebut terlihat adanya kenaikan elevasi dasar saluran di hilir akibat dari sedimentasi yang menyebabkan terjadinya arus balik sehingga tinggi muka air naik di sepanjang saluran. Kemudian terlihat juga elevasi dasar saluran yang tidak beraturan menyebabkan terhambatnya aliran air, sehingga akan menghambat waktu air untuk bergerak saat debit air tinggi. Hasil running ini sejalan dengan penelitian terdahulu [1] yang menyatakan bahwa terjadi arus balik di sungai Krueng Leuhan akibat sedimentasi yang cukup tinggi di muara menuju Krueng Meureubo. Elevasi dasar saluran yang tidak beraturan serta elevasi hilir yang tinggi ini berpotensi besar menjadi masalah utama banjir yang terjadi di Krueng Leuhan.

\subsection{Penanggulangan Banjir}

Permasalahan utama pada saluran ini terletak pada sedimentasi yang berada di hilir saluran, dan juga 
terlihat elevasi saluran yang sangat beragam. Oleh karena itu, tindakan awal yang dilakukan sebagai bentuk penanggulangannya adalah dengan tindakan normalisasi saluran berupa kegiatan galian.

Perencanaan galian ini dilakukan dengan melihat cross section yang terjadi overtopping. Kemudian dilakukan beberapa kali percobaan perencanaan galian yang melibatkan beberapa cross section di sekitarnya dengan cara menentukan kedalaman galiannya. Rencana dimensi saluran setelah pekerjaan galian pada cross section yang dianggap bermasalah dapat dilihat pada tabel berikut.

Tabel 1 Dimensi saluran setelah normalisasi

\begin{tabular}{|c|c|c|c|c|}
\hline \multirow[t]{2}{*}{$\begin{array}{c}\text { Cross } \\
\text { Section }\end{array}$} & $\begin{array}{c}\text { Lebar } \\
\text { Bawah }\end{array}$ & $\begin{array}{c}\text { Lebar } \\
\text { Atas }\end{array}$ & $\begin{array}{c}\text { Tinggi } \\
\text { Tanggul } \\
\text { Kiri }\end{array}$ & $\begin{array}{c}\text { Tinggi } \\
\text { Tanggul } \\
\text { Kanan }\end{array}$ \\
\hline & $(\mathbf{m})$ & $(\mathbf{m})$ & $(\mathbf{m})$ & $(\mathbf{m})$ \\
\hline CS-00 & 14,00 & 19,00 & 6,34 & 6,12 \\
\hline CS-01 & 14,00 & 17,60 & 5,46 & 5,35 \\
\hline CS-02 & 5,00 & 17,70 & 4,50 & 4,05 \\
\hline CS-19 & 5,00 & 21,00 & 2,96 & 2,81 \\
\hline CS-20 & 5,00 & 18,50 & 3,04 & 2,97 \\
\hline CS-21 & 5,00 & 18,40 & 3,05 & 2,97 \\
\hline CS-22 & 16,00 & 18,50 & 3,18 & 3,37 \\
\hline CS-23 & 17,00 & 19,50 & 3,73 & 3,61 \\
\hline CS-25 & 14,00 & 16,20 & 3,17 & 3,26 \\
\hline CS-26 & 20,00 & 22,30 & 3,36 & 3,49 \\
\hline CS-27 & 14,00 & 16,20 & 3,45 & 3,40 \\
\hline CS-28 & 14,00 & 16,20 & 4,11 & 4,15 \\
\hline $\mathrm{CS}-40$ & 12,00 & 26,00 & 3,43 & 3,32 \\
\hline CS-41 & 7,00 & 17,00 & 3,03 & 3,24 \\
\hline CS-46 & 5,00 & 15,00 & 3,11 & 3,36 \\
\hline $\mathrm{CS}-47$ & 5,00 & 14,00 & 3,46 & 3,41 \\
\hline CS-51 & 5,00 & 14,00 & 3,30 & 3,22 \\
\hline CS-52 & 5,00 & 15,00 & 3,63 & 3,32 \\
\hline CS-54 & 5,00 & 14,00 & 3,43 & 3,21 \\
\hline
\end{tabular}

Dari tabel tersebut dapat dilihat bahwa galian yang terdalam berada pada hilir saluran, yakni CS-02 hingga CS-00. Hal ini dikarenakan masalah utama pada saluran ini adalah sedimentasi di hulu saluran. Pekerjaan yang dilakukan hanya berupa galian dasar saluran, sedangkan kelebarannya tetap.

Setelah dilakukan running ulang terhadap penampang saluran yang telah di normalisasi, tidak lagi terdapat overtopping di sepanjang saluran. Gambar profil memanjang saluran setelah normalisasi dapat dilihat pada gambar berikut.

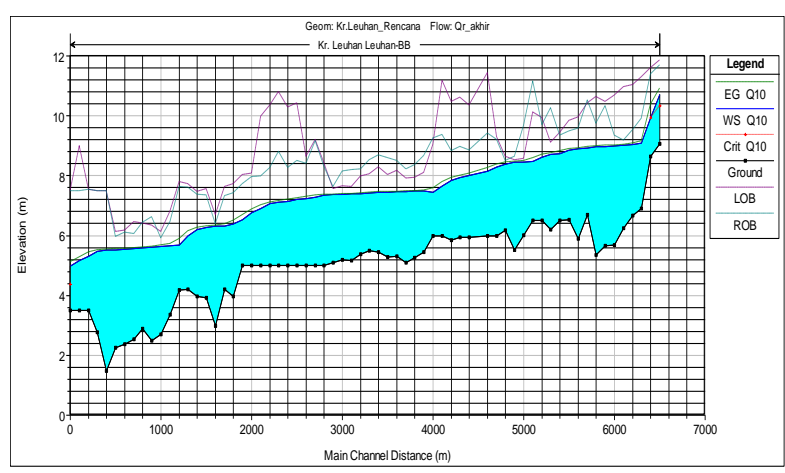

Gambar 2. Profil memanjang sungai Krueng Leuhan setelah normalisasi

Terlihat perbedaan bentuk penampang dari Gambar 2, dimana setelah dinormalisasi, tinggi muka air turun hingga tidak lagi melewati tebing kiri maupun kanan saluran, sehingga dapat disimpulkan Sungai Krueng Leuhan aman dari limpasan banjir pada periode ulang 10 tahun. Perbandingan Gambar 1 dan Gambar 2 juga membuktikan bahwa sedimentasi yang terjadi di hilir saluran sudah sangat tinggi dan berpengaruh besar terhadap aliran salurannya. Hal ini menegaskan bahwa ternyata untuk mengatasi permasalahan yang ada tidak diperlukan perencanaan ulang pada saluran saluran tersebut. Tindakan yang paling efektif adalah menormalisasi saluran tersebut. Hasil simulasi kapasitas penampang saluran setelah normalisasi dapat dilihat pada gambar berikut.

\section{Kesimpulan dan Saran}

\subsection{Kesimpulan}

Hasil evaluasi Sungai Krueng Leuhan dengan merunning debit banjir periode ulang 10 tahun sebesar $35,864 \mathrm{~m}^{3} /$ detik pada 66 cross section di saluran tersebut menggunakan aplikasi HEC-RAS menunjukkan bahwa saluran tersebut tidak lagi mampu menahan debit banjir akibat sedimentasi dan elevasi dasar saluran yang sangat beragam. Dengan permasalahan tersebut, solusi yang ditawarkan adalah normalisasi saluran berupa kegiatan galian dasar saluran pada titik-titik yang menjadi masalah pada saluran tersebut.

Dari hasil running setelah dilakukan normalisasi saluran tidak terlihat lagi adanya overtopping di seluruh penampang saluran, sehingga Sungai Krueng Leuhan aman dari limpasan banjir sampai dengan kala ulang 10 tahun. Tidak dibutuhkan adanya perencanaan ulang terhadap saluran drainase eksisting karena tindakan normalisasi sudah cukup untuk mengatasi banjir. Akan tetapi dibutuhkan tindakan lebih lanjut berupa tindakan 
non-struktural untuk menjaga saluran agar terhindar dari banjir.

\subsection{Saran}

Saran yang dapat diberikan berdasarkan studi yang telah dilakukan adalah penanggulangan banjir dengan normalisasi sungai bukanlah opsi terbaik untuk penanggulangan banjir jangka panjang. Upaya struktural ini akan lebih efektif bila diiringi dengan upaya non-struktural yang bersifat jangka panjang, yaitu dengan pengaturan tata guna lahan, mengedukasi warga setempat untuk tidak membuang sampah di sungai, dan sebagainya.

\section{Daftar Pustaka}

[1] Azmeri, dan I. Satria, An Urban Flood Inundation and Damage Assessment for Disaster Risk Reduction in Johan Pahlawan Subdistrict, West Aceh Regency, IOP Conf. Ser.: Earth Environ. Sci. 630012009

[2] Suripin. Sistem Drainase Perkotaan yang Berkelanjutan. Yogyakarta: Andi Offset, 2004.

[3] Aliyansyah, M., Analisis Hidrolika Aliran Sungai Bolifar dengan Menggunakan HEC-RAS, Tugas Akhir, Jurusan Teknik Sipil Universitas Hasanuddin, 2017

[4] Triatmodjo, B. Hidrologi Terapan. Yogyakarta: Beta Offset, 2009 (a).

[5] Badan Pusat Statistik. Kabupaten Aceh Barat Dalam Angka. Meulaboh: BPS, 2019.

[6] Istiarto. Modul Pelatihan Simulasi Aliran 1Dimensi Dengan Bantuan Paket Pemrograman Hidrodinamika HEC-RAS. Yogyakarta: UGM, 2014.

[7] Triatmodjo, B. Hidrolika II. Yogyakarta: Beta Offset, 1996 (a).

[8] Kodoatie, R.J., dan Sugiyanto. Beberapa Penyebab Banjir dan Metode Pengendaliannya dalam Perspektif Lingkungan. Yogyakarta: Pustaka Pelajar, 2002.

[9] Sebastian, L., "Pendekatan Pencegahan dan Penanggulangan Banjir". Dinamika Teknik Sipil, Vol. 8. No. 2, 2008. 